www.jmscr.igmpublication.org

Impact Factor 3.79

Index Copernicus Value: 5.88

ISSN (e)-2347-176x ISSN (p) 2455-0450

crossref DOI:_http://dx.doi.org/10.18535/jmscr/v4i02.42

Journal Of Medical Science And Clinical Research

IGM Publication

An Official Publication of IGM Publication

\title{
Impact of Duration of Diabetes on Audio-Visual Reaction Time in Type 2 Diabetes Mellitus Patients
}

\author{
Authors \\ Payal Priya $^{1}$, Anshu Khatri ${ }^{2}$, Sharad Kumar Saxena ${ }^{3}$, Avni Bhushan Mowar ${ }^{4}$ \\ ${ }^{1}$ Postgraduate $3,{ }^{2 \& 4}$ Associate Professor, ${ }^{3}$ Professor \\ ${ }^{12}$ Department of Physiology, ${ }^{4}$ Department of Medicine \\ SRMS IMS, Bareilly, UP \\ Corresponding Author \\ Dr Payal Priya \\ B10, Doctor's Residence, SRMS IMS, Bareilly, UP, India \\ Email-vidhilove123@gmail.com Phoneno-8447328913,9458701440
}

\begin{abstract}
Reaction time is an indicator of processing of sensory stimulus by central nervous system and it's execution in the form of motor response. It is found to be delayed in long standing type 2 Diabetes mellitus patients. Reaction time measurement is a simple, non invasive test which can be done in diabetic patients to detect the neuropathic changes earlier. Thereare paucity of studies showing the effect of duration of diabetes on reaction time. Keeping this in mind, present study was planned to compare the audio-visual reaction time of type 2 diabetes mellitus patients of different duration of diabetes with non-diabetic healthy subjects as well as to find the correlation of Auditory Reaction Time and Visual Reaction Time with duration of diabetes in diabetic subjects. Study consisted of ninety documented type 2 DM male patients in the age group of 41-70 years with history of diabetes upto 10 years and who were on oral hypoglycaemic drugs as cases. Cases were divided in three groups on the basis of duration of diabetes (upto 2 years, > 2-5 years and > 5-10 years). Ninetyage matched healthy males were taken as controls. Reaction time was compared between cases and controls according to the duration of diabetes as well as correlation of Audio-visual reaction time with duration of diabetes was done. Present study showedthat Audio-visual reaction time were delayed in patients suffering from diabetes for more than 5 years duration. Along with that significant positive correlation was found between audio-visual reaction time and duration of diabetes in diabetic males. Thus it is concluded that Diabetics have prolonged Audio-visual reaction time. Delayed reaction time in diabetics without symptoms of clinical neuropathy is a sensitive indicator of early nerve damage. Thus, reaction time being a simple, non-invasive, low cost tool might be included in the routine examination of all the patients suffering from type 2 diabetes mellitus.
\end{abstract}

Key words: Neuropathy, Nerve conduction, Cognitive functions, Hyperglycemia, Free radicals, Axonal degeneration. 


\section{Introduction}

Diabetes mellitus (DM) is a group of metabolic diseases which is characterized by high blood sugar either because the body does not produce enough insulin or because cells do not respond to the insulin that is produced ${ }^{[1]}$. The rising prevalence of DM imposes a great burden on health worldwide ${ }^{[2]}$.According to International Diabetes Federation, in 2013, 381 million people had diabetes globally, and by 2030 , this number is estimated to get doubled. The disease currently affects more than 62 million Indians, and by 2035, 109 million individuals will suffer from diabetes [3].

Long standing Type $2 \mathrm{DM}$ is associated with diabetic neuropathy, which is a common cause of morbidity and death among patients with diabetes [4].

Various tests have been employed for detection of peripheral neuropathy in diabetic patients like Diabetic neuropathy symptom (DNS) score, $10 \mathrm{~g}$ Semmes-Weinstein monofilament testing, Vibration testing by $128 \mathrm{~Hz}$ tuning fork, Ankle reflex testing, Vibration perception threshold with a biothesiometer and Reaction time measurement ${ }^{[5]}$. Among these tests, Reaction time (RT) is a simple, non-invasive test, which can easily be done in routine clinical practice. It is the interval between the onset of a signal (stimulus) and the initiation of a movement response ${ }^{[6]}$.It is an indirect index of the processing ability of Central Nervous System and simple means of determining sensory-motor association and performance of an individual ${ }^{[7]}$.It is divided into three parts. The first part is perception time, the time for the application and perception of stimulus. Second part is decision time, which signifies time for giving a suitable response to the stimulus. The third part is motor time, which is the time for the compliance to the order received ${ }^{[8]}$.

Reaction time can be studied by application of various modalities of sensory input like visual, auditory, pain, touch or temperature. The behavioral response is typically a button press but can be an eye movement, a vocal response, or some other observable behavior ${ }^{[9]}$.RT which are commonly used are- ART -Auditory Reaction time, VRT- Visual Reaction Time, CRT Cutaneous Reaction Time and Whole body reaction time ${ }^{[6]}$.Audio-visual reaction time is the time taken by an individual to react to an auditory or visual stimulus respectively ${ }^{[10]}$.

Various studies have shown that reaction time increases significantly in people suffering from long standing DM, and these persons have a higher incidence of postural instability, leading to disabilities $^{[11]}$. Since, Diabetic neuropathies are the commonest cause of neuropathies, and are responsible for significant morbidity, disabilities and reduced life expectancy, hence, screening of neuropathy earlier before it manifests clinically by assessing reaction time is required ${ }^{[12]}$.

Though various studies have been conducted in India showing that reaction time is increased in Diabetic patients, there are paucity of such studies in Northern part of India. Moreover studies which were done previously have not categorized the diabetic patients according to the duration of diabetes. So, keeping these lacunae in mind present study was planned to compare the audiovisual reaction time of type 2 diabetes mellitus patients of different duration of diabetes with nondiabetic healthy subjects as well as to find the correlation of ART and VRT with duration of diabetes in diabetic patients.

\section{Materials and Methods}

The study was undertaken after obtaining the approval from the Institutional human ethical committee in Department of Physiology in collaboration with Department of General Medicine.

Study consisted of ninety documented type $2 \mathrm{DM}$ male patients between the age group of 41-70 years with history of diabetes upto 10 years and who were on oral hypoglycemic drugs as cases. Cases were divided in three groups on the basis of duration of diabetes (upto 2 years, > 2-5 years and $>$ 5-10 years). Ninety age matched healthy males and having normal fasting blood sugar were taken 
as controls. All the subjects had normal vision, normal auditory functions, normal diet and sleep pattern and were right handed. The purpose, procedure and non invasive nature of the study was explained to the subjects and written informed consent was obtained from each subject prior to inclusion in the study. Name, age, sex, address and other necessary details as well as detailed history of the subject including the duration and treatment of diabetes were taken on the prestructured questionnaire.

Patients suffering from Type 1 DM, Type 2 DM patients on insulin therapy, smokers, alcoholics, and subjects suffering from any acute or chronic illness were excluded from the study. Subjects on any kind of medication for long duration other than oral hypoglycemic drugs and who were engaged in any kind of regular physical activity were also excluded.

Fasting blood sugar (FBS) and post prandial blood sugar (PPBS) were estimated by Glucose Oxidase-Peroxidase (GOD-POD) method. Test principle-Glucose present in the plasma is oxidized by the enzyme glucose oxidase (GOD) to gluconic acid with the liberation of hydrogen peroxide, which is converted to water and oxygen by the enzyme peroxidase (POD).

For measuring RT Techno Digital Response Time Apparatus was used, which is a non-invasive tool to measure audio-visual reaction time in seconds. The instrument has two sides separated by a barrier. One side is examiner side, which is for providing stimulus, whereas subject will give response from the opposite side of instrument. On the examiner side, four buttons are present, two on the right side and the other two on the left side. Right side buttons are for providing red and green stimulus (VRT) and left side buttons will produce high and low pitch sounds (ART). On the subject side, corresponding four buttons are present, in which each button is specific for each stimulus. The test was done between 10 am to 12 noon and 3- 4 trials were given to each subject before the actual recording of the reaction time. Initially auditory reaction time was done followed by visual reaction time.

Five readings were taken separately for ART and VRT with an interval of 2-5 seconds, and machine was set at zero level before each recording. Results were displayed on the reaction time apparatus and the lowest value out of 5 readings was taken as the final result.

Statistical Analysis: The results were tabulated separately and statistical results were presented as mean \pm standard deviation (SD). The Statistical Package for the Social Sciences (SPSS) version 21 software analyzer was used. The data were analyzed by unpaired t-test that indicates the level of difference between groups. Pearson's correlation was performed to find the correlation of ART and VRT with duration of diabetes in diabetic patients. $p$ value of $<0.05$ was considered statistically significant.

\section{Results}

Table 1 shows the general characteristics of the cases (diabetic males) in different age groups and varying duration of diabetes and Table 2 depicts the general characteristics of the control males.

In the present study, cases and controls were age and BMI matched ( $\mathrm{p}$ valve $>0.05$ ). Fasting blood sugar was significantly different between two groups ( $\mathrm{p}$ value $<0.05$ ). ART and VRT did not differ significantly when comparison was done between diabetic males upto 2 years as well as upto 5 years duration of diabetes with their age matched healthy controls as depicted in table 3.1 and 3.2.

On the other hand when comparison was done between males suffering from diabetes for more than 5 years with their age matched controls, auditory and visual reaction time were significantly prolonged in cases than controls ( $p$ 0.0001) (Table 3.3).

Table 3.4 shows the significant positive correlation of audio-visual reaction time with duration of diabetes. $(p<0.05)$. 


\section{JMSCR Vol||4||Issue||02||Page 9343-9350||February}

Table 1: General Characteristics Of The Study Population (Cases) Males

\begin{tabular}{|l|l|l|l|}
\hline AGE $(\mathbf{y r s})$ & $\mathbf{4 1 - 5 0}$ yrs $(\mathbf{n = 3 0})$ & $\mathbf{5 1 - 6 0}$ yrs $(\mathbf{n = 3 0})$ & $\mathbf{6 1 - 7 0}$ yrs $(\mathbf{n = 3 0})$ \\
\hline DURATION OF DIABETES $(\mathbf{y r s})$ & Upto 2 yrs & $>2-5 \mathrm{yrs}$ & $>5-10 \mathrm{yrs}$ \\
\hline AGE $(\mathbf{y r s})$ Mean \pm SD & $45.07 \pm 4.40$ & $55 \pm 4.90$ & $65.77 \pm 3.01$ \\
\hline BMI $\left(\mathbf{k g} / \mathbf{m}^{2}\right)$ Mean \pm SD & $22.89 \pm 2.08$ & $22.67 \pm 2.33$ & $22.59 \pm 2.42$ \\
\hline FBS (mg/dl) Mean \pm SD & $139.17 \pm 8.07$ & $145.94 \pm 10.01$ & $157.84 \pm 12.1$ \\
\hline
\end{tabular}

$\mathrm{n}=$ Number of subjects, yrs= Years, BMI - Body mass index, FBS=Fasting blood sugar,

Table 2: General Characteristics Of The Study Population (Controls) Males

\begin{tabular}{|c|c|c|c|}
\hline AGE (yrs) & $41-50$ yrs $(n=30)$ & $51-60$ yrs $(n=30)$ & $61-70$ yrs $(n=30)$ \\
\hline $\operatorname{AGE}(y r s)$ Mean \pm SD & $45.03 \pm 5.65$ & $55.28 \pm 3.90$ & $65.09 \pm 8.63$ \\
\hline BMI $\left(\mathrm{kg} / \mathrm{m}^{2}\right)$ Mean $\pm \mathrm{SD}$ & $22.63 \pm 1.56$ & $21.87 \pm 1.30$ & $21.88 \pm 1.61$ \\
\hline FBS $(\mathrm{mg} / \mathrm{dl})$ Mean \pm SD & $76 \pm 7.42$ & $81.03 \pm 7.01$ & $86.94 \pm 7.91$ \\
\hline
\end{tabular}

$\mathrm{n}=$ Number of subjects, Yrs= years, BMI - Body mass index, FBS=Fasting blood sugar

Table 3.1: Comparison Of Art And VRT In Males With History Of Diabetes Upto 2 Years And Controls (Between Age Group Of 41-50 Years)

\begin{tabular}{|l|l|l|l|}
\hline & $\begin{array}{l}\text { CONTROLS } \\
(\mathbf{n = 3 0})\end{array}$ & $\begin{array}{l}\text { CASES } \\
\text { (DIABETES UPTO 2 years } \\
\text { DURATION) }(\mathbf{n}=30)\end{array}$ & P value \\
\hline $\begin{array}{l}\text { AGE (years) } \\
\text { Mean } \pm \text { SD }\end{array}$ & $45.03 \pm 5.65$ & $45.07 \pm 4.40$ & 0.982 \\
\hline $\begin{array}{l}\text { BMI (kg/m2) } \\
\text { Mean } \pm \text { SD }\end{array}$ & $22.63 \pm 1.56$ & $22.89 \pm 2.08$ & 0.586 \\
\hline $\begin{array}{l}\text { FBS (mg/d) } \\
\text { Mean } \pm \text { SD }\end{array}$ & $76 \pm 7.42$ & $139.16 \pm 8.07$ & $\mathbf{0 . 0 0 0 1 *}$ \\
\hline $\begin{array}{l}\text { ART (seconds) } \\
\text { Mean } \pm \text { SD }\end{array}$ & $0.60 \pm 0.08$ & $0.63 \pm 0.06$ & 0.106 \\
\hline $\begin{array}{l}\text { VRT (seconds) } \\
\text { Mean } \pm \text { SD }\end{array}$ & $0.61 \pm 0.10$ & $0.64 \pm 0.09$ & 0.227 \\
\hline
\end{tabular}

$\mathrm{n}=$ Number of subjects, ART $=$ Auditory reaction time, VRT $=$ Visual reaction time, $\mathrm{p}$ value $<0.05$ significant* 


\section{JMSCR Vol||4||Issue||02||Page 9343-9350||February}

Table 3.2: Comparison Of Art And VRT In Males With History Of Diabetes For > 2-5 Years And Controls (Between Age Group Of 51-60 Years)

\begin{tabular}{|l|l|l|l|}
\hline & $\begin{array}{l}\text { CONTROLS } \\
(\mathbf{n = 3 0})\end{array}$ & $\begin{array}{l}\text { CASES } \\
\text { (DIABETES FOR > 2-5 } \\
\text { years DURATION) } \\
(\mathbf{n = 3 0 )}\end{array}$ & P value \\
\hline $\begin{array}{l}\text { AGE (years) } \\
\text { Mean } \pm \text { SD }\end{array}$ & $55.28 \pm 3.90$ & $55 \pm 4.90$ & 0.807 \\
\hline $\begin{array}{l}\text { BMI (kg/m2) } \\
\text { Mean } \pm \text { SD }\end{array}$ & $21.87 \pm 1.30$ & $22.67 \pm 2.33$ & 0.106 \\
\hline $\begin{array}{l}\text { FBS (mg/dl) } \\
\text { Mean } \pm \text { SD }\end{array}$ & $81.03 \pm 7.01$ & $145.94 \pm 10.1$ & $\mathbf{0 . 0 0 0 1 *}$ \\
\hline $\begin{array}{l}\text { ART (seconds) } \\
\text { Mean } \pm \text { SD }\end{array}$ & $0.75 \pm 0.15$ & $0.78 \pm 0.08$ & 0.338 \\
\hline $\begin{array}{l}\text { VRT (seconds) } \\
\text { Mean } \pm \text { SD }\end{array}$ & $0.81 \pm 0.08$ & $0.82 \pm 0.09$ & 0.651 \\
\hline
\end{tabular}

$\mathrm{n}=$ Number of subjects, ART $=$ Auditory reaction time, VRT $=$ Visual reaction time $\mathrm{p}$ value $<0.05$ significant*

Table 3.3 Comparison Of Art And VRT In Males With History Of Diabetes For >5-10 Years And Controls (Between Age Group Of 61-70 Years)

\begin{tabular}{|l|l|l|l|}
\hline & $\begin{array}{l}\text { CONTROLS } \\
(\mathbf{n}=30)\end{array}$ & $\begin{array}{l}\text { CASES } \\
\text { (DIABETES >5-10 years } \\
\text { DURATION) }(\mathbf{n = 3 0})\end{array}$ & P value \\
\hline $\begin{array}{l}\text { AGE (years) } \\
\text { Mean } \pm \text { SD }\end{array}$ & $65.09 \pm 8.63$ & $65.77 \pm 3.01$ & 0.450 \\
\hline $\begin{array}{l}\text { BMI (kg/m2) } \\
\text { Mean } \pm \text { SD }\end{array}$ & $21.88 \pm 1.61$ & $22.59 \pm 2.42$ & 0.186 \\
\hline $\begin{array}{l}\text { FBS (mg/dl) } \\
\text { Mean } \pm \text { SD }\end{array}$ & $86.94 \pm 7.91$ & $157.84 \pm 12.01$ & $\mathbf{0 . 0 0 0 1 *}$ \\
\hline $\begin{array}{l}\text { ART (seconds) } \\
\text { Mean } \pm \text { SD }\end{array}$ & $1.00 \pm 0.19$ & $1.70 \pm 0.21$ & $\mathbf{0 . 0 0 0 1 *}$ \\
\hline $\begin{array}{l}\text { VRT (seconds) } \\
\text { Mean } \pm \text { SD }\end{array}$ & $1.09 \pm 0.20$ & $1.76 \pm 0.25$ & $\mathbf{0 . 0 0 0 1 *}$ \\
\hline
\end{tabular}

$\mathrm{n}=$ Number of subjects, ART $=$ Auditory reaction time, VRT $=$ Visual reaction time, $\mathrm{p}$ value $<0.05$ significant*

Table 3.4 Pearson's Correlation Of Art And VRT With Duration Of Diabetes In Diabetic Males (Between Age Group Of 41-70 Years)

\begin{tabular}{|l|l|l|}
\hline PARAMETERS & ART (seconds) & VRT (seconds) \\
\hline DURATION OF & r value $=0.436$ & r value $=0.450$ \\
DIABETES (years) & p value $=<0.01^{*}$ & p value $=<0.01^{*}$ \\
\hline
\end{tabular}

$\mathrm{P}$ value $<0.05$ significant* 
Figure 1.1 Pearson's Correlation Of Art With Duration Of Diabetes In Diabetic Males

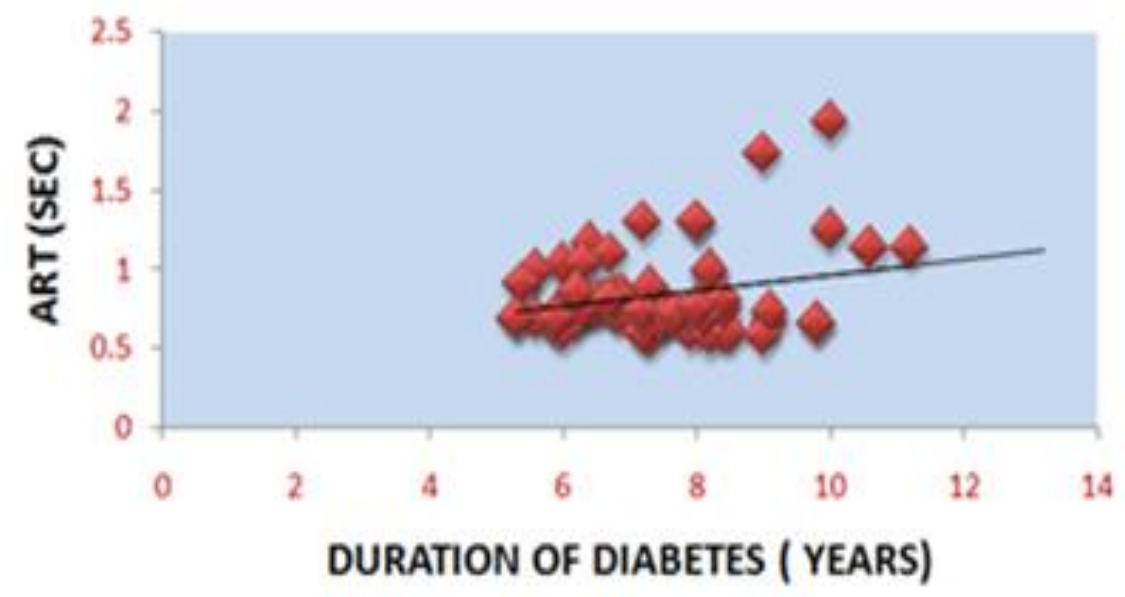

Figure 1.2 Pearson's Correlation Of VRT With Duration Of Diabetes In Diabetic Males

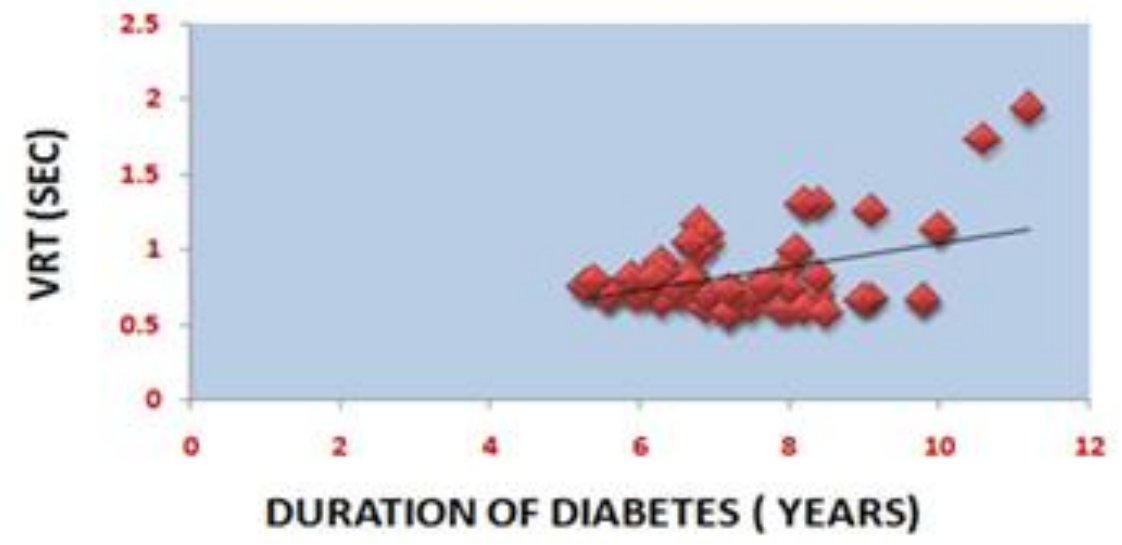

\section{Discussion}

The insidious onset of Type 2 Diabetes Mellitus and the long duration of asymptomatic period makes the prevalence of complications quite high at the time of its diagnosis. So, the screening tests for complications at the time of diagnosis becomes imperative not only for early detection, but also to prevent its progression to end stage diseases $^{[13]}$.

One such test is Reaction time (RT), which is the time interval between the onset of a signal (stimulus) and the initiation of a movement response. It is an index of processing ability of the central nervous System ${ }^{[14]}$. Reaction time is a simple, non-invasive test, and can be done easily without much expertancy. So, this study was undertaken to study the effect of duration of diabetes on audio-visual reaction time.

The finding of present study revealed that, when males suffering from diabetes upto 2 years duration were compared with their age matched healthy controls, ART and VRT did not differ significantly between two groups. In fact, similar results were found when male diabetics for $>2$ to 5 years duration were compared with their age matched healthy controls.

On the contrary, males having diabetes for $>5$ to 10 years had prolonged ART and VRT when compared with their age matched controls and it was statistically significant $(\mathrm{P}<0.05)$.

These findings are similar to the study done previously by Joginder et al in 2015, which showed that auditory and visual reaction times 
were significantly higher in people suffering from diabetes for $>5$ years duration in the age group of 30-50 years compared to their age matched controls. But they have not taken into account the patients suffering from diabetes below 5 years of duration of diabetes. Moreover they did not comment on males and females data separately ${ }^{[1]}$.

Parekh et al and Shreechakradhar et al found similar results in their study that audio-visual reaction time of patients with type $2 \mathrm{DM}$ were significantly higher as compared to those of normal subjects. But in these studies they also did not categorize the diabetic patients according to the duration of diabetes as well as they did not analyzed males and females separately ${ }^{[11],[15] \text {. }}$

Present study also revealed significant positive correlation of audio-visual reaction time with duration of diabetes $(\mathrm{P}<0.05)$.

Vedavathi et al also found significant positive correlation of reaction time with diabetic duration ${ }^{[14]}$.On the contrary, Vitthal et al found no significant positive correlation between duration of diabetes and whole body $\mathrm{RT}^{[16]}$.

Present study clearly shows that ART and VRT were delayed in patients suffering from diabetes for more than 5 years. Along with that significant positive correlation was found between ART and VRT with duration of diabetes.

Thus, from the present study we can draw the inference that, Type 2 Diabetes Mellitus affects the peripheral nerves, slows psychomotor responses and has cognitive effects on those individuals who are suffering from long standing disease. It affects the peripheral nerves in the somatosensory, visual and auditory system, which are responsible for delayed reaction time to auditory and visual stimuli ${ }^{[1]}$.

In long standing cases of diabetes mellitus, hyperglycemia is the main culprit for the development of peripheral neuropathy. Hyperglycemia is responsible for the free radicals generation, which are responsible for the oxidative stress and hence for the development of various complications of diabetes ${ }^{[17]}$.
The production of reactive oxygen species (ROS) is under tight control in healthy cells, but overproduction during metabolic dysfunction leads to cellular injury. Superoxide $\left(\mathrm{O}^{-}\right)$, hydrogen peroxide (H2O2), and nitric oxide (NO) are three free radical reactive oxygen species.These agents together produce highly active singlet oxygen, hydroxyl radicals, and peroxynitrite that can attack proteins, lipids and DNA. In addition, both $\mathrm{O}^{-}$and $\mathrm{NO}$ can attack iron-sulfur centers of enzymes and other proteins to release iron atoms and consequently inhibit enzyme/protein activities ${ }^{[17]}$.

All these changes found in patients suffering from long standing type 2 diabetes mellitus leads to defective axonal transport, axonal fragmentation and degeneration of both myelinated and unmyelinated nerve fibres, axonal shrinkage, finally impaired signal transmission of nerves and delayed motor nerve conduction velocity ${ }^{[1],[12]}$.

\section{Conclusion}

Diabetics have prolonged Audio-visual reaction time and delayed reaction time in diabetics without symptoms of clinical neuropathy is a sensitive indicator of early nerve damage.

Thus, reaction time being a simple, non-invasive, low cost tool, might be included in the routine examination of all patients suffering from type 2 diabetes mellitus. This will also help to know the progression of the disease as well as the effectiveness of the intervention. Further research needs to be done to establish a relationship between neural processing deficits and the pathological processes produced by long standing Diabetes Mellitus.

\section{References}

1. J. Sidhu, S. Mittu S , H. Sidhu, "Comparative study of reaction times in type 2 diabetics and non- diabetics," Scholars journal of applied medical sciences, 3 (1G) ,527-529, 2015.

2. P. O. U.Adogu, H. N. Chineke, M. U. Ewuzie , O. O.Enwere, N. B Egenti, “The 
Prevalence and Presentation Pattern of Diabetes Mellitus in Patients at Imo State University Teaching Hospital (IMSUTH) Orlu and Imo State Specialist Hospital (IMSSH) UmugumaOwerri (A 10-Year Retrospective Study: 1st November 2004 to 31st October 2013)" JDM, 5 (2), 49-57 , May 2015.

3. Epidemiology of diabetes mellitus. Wikipedia, the free encyclopedia. April 2015 (http://en.wikipedia.org/w/index.php)

4. Gerald, "Diabetic neuropathy-a review" Nature Clinical Practice Neurology, 3 , 331-340, 2007.

5. U. Bedi, G. Mittal, "Efficacy of Simple Bed Side Methods in Diagnosing Peripheral Neuropathy in Diabetic Patients in Comparison with Vibration Perception Threshold" Research Journal of Pharmaceutical, Biological and Chemical Sciences, (4), 1178-1184, December 2012.

6. N. Begum, S. Kumaran, G. Venkatesh, S.B.Kulkarni, "Study of the utility of short course of yoga to improve Reaction time" Jounal of Clinical and Diagnostic Research, 6(7) , 1241-1243, 2012.

7. S. Das, A. Gandhi, S. Mondal, "The effect of premenstrual stress on the audiovisual reaction time" Indian Jornal Of PhysiolPharmacol, 41, 67-70, 1997.

8. R. S.Tripo, "How fast can you react" Sci Dig, 57, 1965.

9. S. Bamania, C. Parmar, "Assessment of visual reaction time in controlled and uncontrolled type 2 diabetic patients" Indian Journal of Applied Research, 5(1), 523-525, January 2015.

10. G. B.Taware , M.V.Bhutkar, P.M.Bhutkar, V.P.Doijad, A.O.Surdi, "Effect of age on audiovisual and whole body reaction time" AL Ameen J Med Sci, 5 (1), 9094,2012.
11. N.Parekh, I.P.R.Gajbhiye , M. Wahane, J.Titus, "The study of auditory and visual reaction time in healthy controls, patients of diabetes mellitus on modern allopathic treatment, and those performing aerobic exercises" Indian Academy Of Clinical Medicine, 5(3), 239-243, July -sept 2004.

12. M. Muhil, U. Sembian, Babita, N. Ethiya, K. Muthuselvi, " Study of Auditory, Visual Reaction Time and Glycemic Control (HBA1C) in Chronic Type II Diabetes Mellitus" Journal of clinical and diagnostic research, 8(9), 11-13, Sep 2014.

13. S.R.Mehta, A.S. Kashyap ,S.Das, "Diabetes Mellitus in India: The Modern Scourge" MJAFI, 65(1), 50-54,2009.

14. K. J. Vedavathi , G. Venkatesh, K.R. Shekharappa,"Study of Reaction Time and Glycated Hemoglobin (HbA1c) in T2DM Patients" Research Journal of Pharmaceutical, Biological and Chemical Sciences,4(2), 1099,2013.

15. S. U.Mungal," Comparative study of audio-visual reaction time in patients with type 2 diabetes and in normal subjects"Nationaljounal of physiology, 5(1), July 2014.

16. V. Khode, J. Sindhur, S. Ramdurg, K. Ruikar, S. Nallulwar, "Chronoscopic reading in whole body reaction times can be a tool in detecting cognitive dysfunction in type 2 diabetics: A case control study" 2015.

17. M. Vincent , J. W. Russell , P. Low, E.L.Feldman, " Oxidative stress in the pathogenesis of diabetic neuropathy Endocrine Reviews" 25(40), 612-628 , 2014. 